\title{
Vaccines, Routes of Administration and Adjuvants with Focus on Caseous Lymphadenitis
}

Daniela Droppa-Almeida ${ }^{1 *}$, Elton Franceschi ${ }^{1}$, Francine Ferreira Padilha ${ }^{1}$ and Katharina Kelly Oliveira Gama Silva ${ }^{2}$

${ }^{1}$ Postgraduate Program in Industrial Biotechnology, PIB Tiradentes University, UNIT - Aracaju/SE, Brazil

${ }^{2}$ Biomedical researcher at Heart Hospital, Aracaju/SE, Brazil

*Corresponding author: Daniela Droppa-Almeida, Postgraduate Program in Industrial Biotechnology, PIB Tiradentes University,UNIT - Aracaju/SE, Brazil, E-mail: danieladroppa@gmail.com

Received September 12, 2017; Accepted November 20, 2017; Published November 22, 2017

\section{Retraction Note:}

The article entitled "Vaccines, Routes of Administration and Adjuvants with Focus on Caseous Lymphadenitis" has been accepted for publication in the Clinical Microbiology: Open Access considering the statements provided in the article as personal opinion of the author which was found not having any conflict or biasness towards anything. As the article was a perspective one, information provided by the author was considered as an opinion to be expressed through publication.

Publisher took decision to make the article online solely based on the reviewers suggestion which considered the article not but a personal opinion of the author. However, it is found that the author have some personal concerns and issues, therefore, being retracted from the journal.

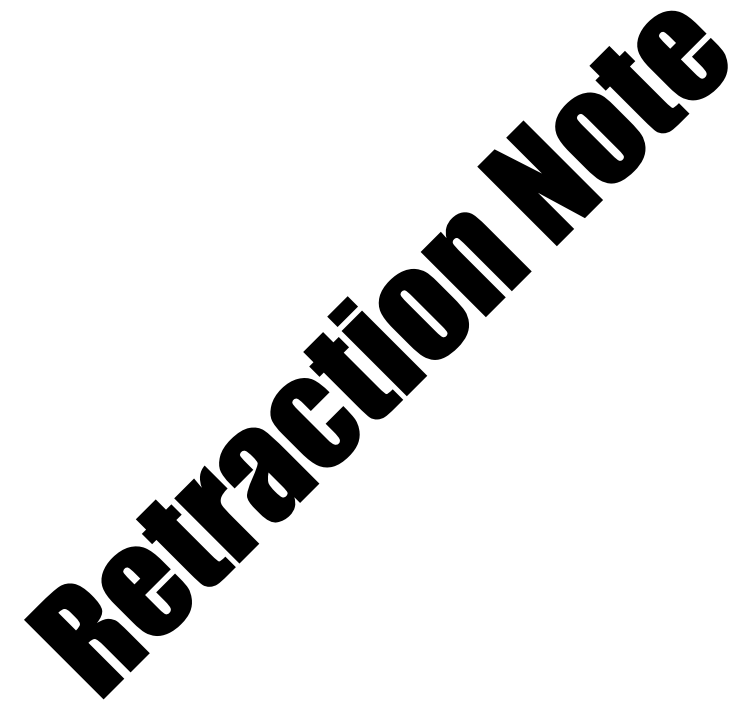

